\title{
Micronutrients as adjunct therapy of acute illness in children: impact on the episode outcome and policy implications of current findings
}

\author{
Dilip Mahalanabis* and Maharaj K. Bhan \\ Society for Applied Studies, Calcutta and All India Institute of Medical Sciences, New Delhi, India
}

\begin{abstract}
Role of micronutrients namely vitamin A, zinc and folate, as adjunct therapy of illness episodes in children in developing countries have been discussed in the light of health policy. Apart from a selective review, attempts have been made to statistically combine results of several studies to address policy issues. In children, vitamin A supplementation during illness has (a) a profound effect in reducing mortality in measles, (b) possibly a significant effect in reducing persistent diarrhea episodes in children with acute diarrhea, and (c) no benefit in pneumonia.

Use of large dose vitamin A is recommended during measles episodes but not in non-measles pneumonia. Its use in acute diarrhea is debatable but recommended in persistent diarrhea and in severe malnutrition as a component of a micronutrient mixture. Large dose vitamin A supplementation should be used with caution in young infants as there are unresolved concerns about its safety particularly, bulging fontanelle observed in infants when co-administered at immunization. In children, zinc supplementation during illness, (a) had a marked effect in reducing prolonged episodes and a modest effect on episode duration in acute diarrhea, (b) resulted in reduced rate of treatment failure and death in persistent diarrhea, (c) had no effect in measles and non-measles pneumonia, and (d) probably had a detrimental effect of increasing death rate when a large dose was used in severely malnourished children. The desirability of routine zinc supplementation therapy of undernourished children with acute diarrhea should be assessed further. Concerning policy, zinc supplementation as a component of a micronutrient mixture is recommended in the rehabilitation of severely malnourished children and in persistent diarrhea. However, recommendation for its routine use in all cases of acute diarrhea in children needs additional studies on effectiveness, cost, operations and safety. In two randomized controlled trials folate has been evaluated in acute and persistent diarrhea and found to have no beneficial effect. Folate is not recommended as adjunct therapy of diarrhea. Role of folate in preventing severe disease and/or death deserves further evaluation.
\end{abstract}

\section{Micronutrients: Treatment: Diarrhea: Pneumonia: Children: Zinc: Vitamin A: Folate}

Many micronutrients are known to be essential in the human diet; but only three of them — vitamin A, iron and iodine are accepted to be commonly deficient and global intervention programmes have been launched to combat their deficiency. In addition, folate supplementation during pregnancy is also included among the essential public health measures largely to prevent congenital anomalies. However, there is a growing body of evidence that zinc might also be included in this category. In this discussion, however, we restrict ourselves to the role of micronutrients as adjunct therapy of clinical illness and the related policy implications for case management strategies for diseases of public health importance.

It is pertinent to make a general comment on policy issues. Decision making is an issue of judgement based on both scientific knowledge and ethical considerations. It is important to critically examine the benefits, costs and risks.
For a policy decision on the use of micronutrients for illness episodes, there is a need to consider the magnitude of the effect (i.e. large enough to be worthwhile), the operational questions related to its introduction into primary health care, training of people in correct use, supplies and cost, and the potential problem of multiple doses due to frequent and/or repeated illness. There is also the issue of cost competition with other highly worthwhile interventions such as oral rehydration in the case of diarrhea.

In this paper, we discuss the role of supplementation with vitamin A, zinc and folate during an acute illness and based on the present evidence, the policy recommendations for their use.

\section{Vitamin A: therapeutic use}

A large number of studies conducted in developing countries evaluated the role of periodic supplementation

\footnotetext{
* Corresponding author: Dr Dilip Mahalanabis, Society for Applied Studies, 108, Manicktala Main Road, Flat-3/21, Calcutta — 700054, India, fax +91333376290, emaildmahalanabis@vsnl.com
} 
Table 1. The impact of vitamin A administered during acute diarrhea on episode outcome

\begin{tabular}{|c|c|c|c|}
\hline & Age & Impact & Comment \\
\hline $\begin{array}{l}\text { Henning et al. } 1992 \\
n=83 \\
\text { Severe watery diarrhea } \\
\text { Dose }=60000\end{array}$ & $1-5 y$ & $\begin{array}{l}\text { No effect on severity, duration or risk } \\
\text { of persistence }\end{array}$ & $\begin{array}{l}\text { Trial size was too small to } \\
\text { assess the impact and } \\
\text { persistence of diarrhea }\end{array}$ \\
\hline $\begin{array}{l}\text { Bhandari et al. } 1997 \\
\text { Vitamin } A=451 \\
\text { Placebo }=444 \\
\text { Dose }=60 \text { 000 RE community based } \\
\text { treatment of diarrhea }\end{array}$ & $1-5 y$ & $\begin{array}{l}\text { No effect on duration } \\
\text { Marked reduction in diarrhea } \\
>14 \text { days } \\
\text { Marked difference in all parameters in } \\
\text { non-breast-fed group }\end{array}$ & $P=0.02$ \\
\hline $\begin{array}{l}\text { Faruque et al. } 1998 \\
\text { Vitamin } \mathrm{A}=341\end{array}$ & $6-24 \mathrm{~m}$ & $\begin{array}{l}\text { No effect on diarrhea duration } \\
\text { A trend for reduction in diarrhea } \\
>7 \text { days }(-33 \%)\end{array}$ & $\begin{array}{l}P=0.41 \\
P=0.089\end{array}$ \\
\hline $\begin{array}{l}\text { Placebo }=340 \\
\text { Dose }=60000 \mathrm{RE} \\
\text { Hospitalized (short stay) patients } \\
\quad \text { followed into the community }\end{array}$ & & $\begin{array}{l}\text { A trend for reduction in diarrhea } \\
>14 \text { days }(-33 \%)\end{array}$ & $P=0.43$ \\
\hline $\begin{array}{l}\text { Hossain et al. } 1998 \\
\text { Vitamin } A=42 \\
\text { Placebo }=41 \\
\text { Dose }=60000 \mathrm{RE} \\
\text { Dysentery due to shigellosis }\end{array}$ & $1-7 y$ & $\begin{array}{l}\text { Clinical cure on day } 5 . \text { rate ratio }=0.68 \\
(\mathrm{Cl}=0.50,0.93) \text { i.e. hastens clinical cure }\end{array}$ & $P=0.02$ \\
\hline
\end{tabular}

of children aged 6 months to 5 years with vitamin $\mathrm{A}$ in preventing death and disease. A meta-analysis (Beaton et al. 1992) of such studies concluded that periodic supplementation with vitamin A substantially reduces the overall mortality in these children. A few studies that examined the cause-specific mortality showed that while mortality associated with diarrhea and measles was reduced, there was no effect on pneumonia associated mortality. One inadequately explained finding, however, was that these studies did not show a significant effect on the overall morbidity. It has been postulated that the effect on mortality is largely due to a decrease in the rate of severe disease associated with diarrhea, measles, malnutrition and other infections. There is evidence, discussed later in this review, that the effect of vitamin A supplementation of children with acute diarrhea may be substantial in reducing the rate of persistent diarrhea episodes. It may be noted that a large proportion of diarrhea associated mortality in children is associated with persistent diarrhea. In light of the remarkable benefit from vitamin A supplementation in reducing mortality in countries where its deficiency is common, we examine its role during illness episodes.

\section{Vitamin A supplementation during acute diarrhea}

Four therapeutic trials conducted to examine the beneficial effect of vitamin A as adjunct therapy during acute diarrhea are summarized in Table 1. In the first placebo controlled trial, administration of an oral dose of $60000 \mu \mathrm{g} \mathrm{RE}$ to eighty-three 1-5-year-old hospitalized children with severe watery diarrhea did not show any significant reduction in the purging rate or the duration of the episodes (Henning et al. 1992). In a community-based treatment trial in India, Bhandari et al. (1997) administered $60000 \mu \mathrm{g}$ RE to 900 children aged $1-5$ years old and showed a $70 \%$ reduction in the episodes of persistent diarrhea (i.e. duration $>14$ days) but no impact on average episode duration. In a subgroup analysis, they showed that in non-breast-fed

Table 2. Impact of vitamin A supplementation during acute diarrhea on risk of persistent diarrhea

\begin{tabular}{|c|c|c|}
\hline Studies & Rate ratio $(95 \% \mathrm{Cl})$ & $P$ value \\
\hline \multicolumn{3}{|l|}{ 1. Bhandari et al. 1997} \\
\hline (a) Vitamin $A=451$, Placebo $=444$ & \multirow{3}{*}{$\begin{array}{c}0.30(0.10,0.92) \\
-^{*}\end{array}$} & \\
\hline (b) Non-breast-fed subgroup & & \multirow{2}{*}{0.003} \\
\hline $\begin{array}{l}\text { Vitamin } A=244, \text { Placebo }=223 \\
\text { Dose }=60000 \mathrm{RE}\end{array}$ & & \\
\hline 2. Faruque et al. 1998 & \multirow[t]{4}{*}{$0.66(0.24,1.85)$} & \multirow[t]{4}{*}{0.43} \\
\hline Vitamin $\mathrm{A}=341$, Placebo $=340$ & & \\
\hline $6-24$ months & & \\
\hline Dose $=60000 \mathrm{RE}$ & & \\
\hline Combined weighted †RR \& $95 \% \mathrm{Cl}(1 \mathrm{a}+2)$ & $0.45(0.21$ to 0.94$)$ & 0.046 \\
\hline Combined †RR \& $95 \% \mathrm{Cl}(1 \mathrm{~b}+2)$ & $0.34(0.14$ to 0.86$)$ & 0.029 \\
\hline
\end{tabular}

* One cell has zero value. Greenland \& Robins, 1985 †RR $=$ Rate ratio. 
children there was a significant improvement in all the parameters compared. These findings are plausible given that breast-feeding is known to protect against severe vitamin A deficiency. In a recent study, $60000 \mu \mathrm{g} \mathrm{RE}$ administered to 341 children aged 6-24 months had no effect on diarrheal duration and there was some trend for reduction in prolonged (i.e. more than 7 days) and persistent diarrhea episodes (Faruque et al. 1998). More recently, Hossain et al. (1998) reported a study on eightythree, 1-7-year-old children suffering from severe dysentery due to shigellosis where a dose of $60000 \mu \mathrm{g} R E$ led to an improvement in the clinical cure rate on day 5 by $32 \%$.

We evaluated the role of vitamin A therapy of acute diarrhea in preventing persistent diarrhea episodes (i.e. duration $>14$ days) by statistically combining the results (Greenland \& Robins, 1985) of two large trials conducted in South Asia (Bhandari et al. 1997; Faruque et al. 1998). In a combined analysis of the data from these two studies in which 792 children received vitamin A and 784 children received placebo, the effect of vitamin A supplementation was substantial in reducing the rate of persistent diarrhea episodes (55\% reduction, $95 \%$ CI $6 \%, 79 \%$; Table 2 ). The known beneficial effect of vitamin A on immune function and mucosal repair may partly explain this effect.

\section{Vitamin A supplementation of children with measles: effect on mortality}

Large dose vitamin A supplementation of hospitalized children with measles markedly reduced measles-associated mortality. Four randomized controlled trials of vitamin $A$ in children with measles are summarized (Table 3). We have attempted to statistically combine (Greenland et al. 1985) the results of these four studies to arrive at a weighted rate ratio for mortality from measles with and without vitamin A supplementation. In one of the earliest studies where cod liver oil was used as a source of vitamin $\mathrm{A}$, a dramatic impact in reducing the mortality rate by $44 \%$ was shown (Ellison, 1932). Combining these results with the three recent studies gives us a sample size of 509 children in the vitamin A group and 520 in the control group. The reduction in the mortality rate was as high as $54 \%$ (95\% CI $18 \%$, $72 \%)$. This approach of combining studies to achieve greater statistical power, though useful, is limited by the fact that a systematic effort was not done to locate all unpublished studies.

\section{Vitamin A treatment of non-measles childhood pneumonia}

Four vitamin A treatment trials conducted in children with acute lower respiratory infections (one in children with clinical diagnosis of pneumonia) in Guatemala (Kjolhede et al. 1995), USA (Quinlan KP \& Hayanike, 1996), Tanzania (Fawzi et al. 1996) and North Brazil (Nacul et al. 1997) failed to show a beneficial impact of vitamin A on the clinical course of illness. In the latter two trials relatively larger doses of vitamin A were used (comparable to the most effective measles trials) in a population likely to be vitamin A deficient. In the study in Brazil, there was some suggestion (but not proven) that severely affected children with pneumonia may benefit.

The mechanism by which vitamin A reduces mortality is not fully understood. The two leading causes of death in children are lower respiratory infections and diarrheal diseases. While vitamin A supplementation was shown to be associated with reduced diarrhea associated mortality, reduced mortality from acute lower respiratory infections was noted only in measles studies. Interestingly, vitamin A supplementation reduced deaths from other causes by about $34 \%$ (of all causes of death). It is possible that deaths from other causes largely include malnutrition and other infectious illnesses. The discrepancy between lack of effect of vitamin A supplementation on morbidity and substantial impact on mortality still remains speculative. The beneficial effect of vitamin A on the mucosal integrity and on the immune response may act differentially in the intestinal (IgA) and respiratory mucosa ( $\mathrm{IgG})$.

There are other plausible explanations. Vitamin A deficiency exacerbates damage to the mucosa by pathogens as demonstrated in experimental rotavirus infections (Ahmed et al. 1990; Zile et al. 1977; Nzegwu \& Levin, 1992). Intestinal bacterial translocation with increased risk of systemic sepsis has also been postulated in vitamin A deficiency for which some experimental evidence has recently been provided (Shoda et al. 1996) and is summarized later. Furthermore, vitamin A deficiency is associated with impaired mucosal immune and nonimmune defense, mucosal IgA, mucus production, reduction in goblet cells (Welsh et al. 1998; Gmoshinaldi et al.

Table 3. Vitamin A supplementation of children with measles: effect on mortality

\begin{tabular}{|c|c|c|c|c|c|c|}
\hline \multirow[b]{2}{*}{ Studies, Vit. A dose } & \multirow[b]{2}{*}{ Age } & \multicolumn{2}{|c|}{ Mortality } & \multirow[b]{2}{*}{ Rate ratio } & \multirow[b]{2}{*}{$95 \% \mathrm{Cl}$} & \multirow[b]{2}{*}{$P$ value } \\
\hline & & Vit. A & $\overline{\text { Control }}$ & & & \\
\hline Barclay et al. 198760000 RE twice & $6 y$ & $6 / 88$ & $12 / 92$ & 0.52 & 0.21 to 1.33 & 0.16 \\
\hline Hussey \& Klein, 199060000 RE twice & $<13$ y & 2/92 & $10 / 97$ & 0.21 & 0.05 to 0.94 & 0.022 \\
\hline Coutsoudis et al. 1991,108000 RE twice & 9-24 m & $0 / 29$ & $1 / 32$ & - & - & 0.52 \\
\hline Ellison,1932, Cod liver oil & $5 \mathrm{y}$ & $11 / 300$ & $26 / 300$ & 0.56 & 0.28 to 1.12 & 0.097 \\
\hline Combined weighted RR (Mantel-Haenszel,1959) & - & $19 / 509$ & $49 / 520$ & 0.46 & 0.28 to $0.78 \dagger$ & 0.0038 \\
\hline
\end{tabular}

\footnotetext{
* Note: Individually randomized except Ellison's (allocated by ward). No patient was excluded from analysis in any of the studies. Excluding Ellison's study gives weighted rate ratio $0.36(95 \% \mathrm{Cl} 0.17,0.79)$.
}

† Greenland-Robins confidence interval. 
Table 4. Vitamin A and folate resist enteric bacterial translocation in a rat model of lectin induced diarrhea

\begin{tabular}{lccc}
\hline & \multicolumn{3}{c}{ Bacterial counts (Log CFU/g) } \\
& *Vit. A $(n=6)$ & Control $(n=6)$ & $P$ \\
\hline Jejunal mucosa & $2.4 \pm 1.39$ & $2.63 \pm 1.33$ & NS \\
Mesenteric lymph nodes & $3.53 \pm 0.77$ & $4.03 \pm 0.86$ & $<0.05$ \\
& & & \\
& $\dagger$ Folic acid $(n=5)$ & Control $(n=5)$ & $P$ \\
Jejunal mucosa & $0.400 \pm 0.894$ & $1.416 \pm 1.312$ & 0.17 \\
Mesenteric lymph nodes & $1.835 \pm 1.070$ & $3.392 \pm 0.821$ & 0.042 \\
\hline * Shoda et al. 1996. & & & \\
† Shoda \& Mahalanabis (unpublished).
\end{tabular}

1987). Finally, vitamin A deficiency adversely affects the expression of transforming growth factor, a putative regulator of epithelial growth and differentiation and restitution of damaged mucosa (Glick et al. 1991; Gudas et al. 1994; Dignosis \& Podolsky, 1993).

\section{Vitamin A and folate resist enteric bacterial translocation and thus prevent septicemic complications: experimental evidence}

In a rat model of lectin induced diarrhea with translocation of enteric bacteria into mesenteric lymph nodes, vitamin A supplementation (intraperitoneal) was evaluated in its role for preventing translocation (Shoda et al. 1996). In a similar unpublished study by the same authors, the role of oral folic acid supplementation in reducing the severity of bacterial translocation in rats was also evaluated. Summary results from these two studies are shown in Table 4. Both vitamin A and folic acid supplementation significantly reduced enteric bacterial translocation from the small intestine into the mesenteric lymphnodes. We hypothesize that at least, part of the effect of vitamin A in reducing mortality may be mediated through prevention of septicemic complications by blocking bacterial translocation either from the intestine or from the respiratory mucosa, particularly in malnourished children. It should be noted that effect of vitamin A administration on sepsis has not been studied in the trials reported so far.

\section{Safety of large dose vitamin A in infants}

The safety of administering vitamin A with vaccines has been evaluated in five controlled intervention studies (Baqui et al. 1995; de Francisco et al. 1993; Mahalanabis et al. 1997; Rahman et al. 1995; Stabell-Benn et al. 1995). Recently the WHO has also promoted a multicentre randomized trial (WHO, 1998) to assess the benefits and safety of a smaller dose of $25000 \mathrm{IU}$ vitamin A linked to DPT/OPV immunization at 6,10 and 14 weeks of age. The first five studies used vitamin A doses ranging from 75000 to $200000 \mathrm{IU}$ along with vaccines and reported bulging fontanelle in a small proportion of infants within 48 hours of vitamin A administration. In the WHO multicentre trial, although a larger proportion of vitamin A than placebo recipients had bulging fontanelle within 48 hours, fewer than $1 \%$ in either group were affected. The bulging fontanelle was however, transient and no sequelae were observed over short-term follow up. This aspect of safety was however, not studied in the context of treating illness episodes.

\section{Large dose vitamin A in acute illness: policy issues}

A single large dose of vitamin $\mathrm{A}$ in the treatment of clinically severe measles is recommended by the WHO, which is well supported by evidence from controlled clinical trials.

Use of vitamin $\mathrm{A}$ as a component of a micronutrient mixture (2 RDA) daily to treat persistent diarrhea and severe malnutrition is recommended by the $\mathrm{WHO}$ as a part of the case-management strategy in developing countries.

The use of a single large dose of vitamin A to treat each episode of acute diarrhea in infants and children to prevent persistent diarrhea in countries where vitamin A deficiency is common is debatable. Of concern is its use in young infants and children who may suffer from frequent attacks of diarrhea leading to many large doses of vitamin A if used; this would be particularly true in countries where periodic large dose vitamin A supplementation of children is a public health policy.

Addition of vitamin A for the treatment of childhood pneumonia is not recommended.

Bulging fontanelle observed in a small proportion of infants associated with large dose vitamin A administration along with childhood immunizations was transient in nature and no adverse sequelae have so far been reported.

\section{Zinc: therapeutic use}

The impact of zinc supplementation on childhood infectious diseases has recently been reviewed (see Black \& Sazawal, 2001, this issue). Our discussion focuses on a few selected issues regarding the role of zinc as adjunct therapy of illness episodes.

Zinc as a micronutrient plays a key role at the catalytic sites of a wide and heterogenous range of enzymes and pervades all metabolic pathways. It is involved in the maintenance of ion channels and integrity of biomembranes, in the structure and function of hormone receptors, in the fundamental processes of cellular growth and differentiation and appears to be a regulatory ion for gene expression. Probably of relevance to our discussion is the role of zinc in cell growth and differentiation which would make the young growing organisms as well as cells with rapid turnover such as the cells of the immune and gastrointestinal systems vulnerable to zinc deficiency. In animal models zinc deficiency is associated with impaired sodium and water transport (Ghishan, 1984; Patrick et al. 1978; Patrick et al. 1980; Roy et al. 1986), impaired cellular immunity and intestinal secretory antibody production.

Unlike other micronutrients of public health importance (such as eye signs associated with vitamin A deficiency), zinc deficiency is not associated with specific clinical features nor are there any specific and reliable biomarkers of deficiency which could be used in evaluating populations for mild to moderate zinc deficiency. While it appears 
likely that mild to moderate zinc deficiency affects a significant proportion, health consequences of milder deficiency are not known. We are therefore, dependent on controlled intervention trials with zinc supplementation to provide valuable information not only on the beneficial role of zinc supplementation but also on the existence of zinc deficiency among the study population.

It has been suggested that in developing countries low dietary zinc and its poor bioavailability may lead to suboptimal zinc status in children. Phytate in traditional staples like cereals, legumes and tubers and a high phytate: zinc ratio make zinc poorly bioavailable. Furthermore, low birth weight infants have low stores of zinc and prevalence of low birth weight is very high in many developing countries particularly in South Asia. After 6 months, nearly two thirds of the zinc requirement have to be met from complementary foods even in breast-fed infants. It is, therefore, likely that subclinical zinc deficiency is common in developing countries with adverse consequences on health. Recently, a large number of clinical trials and field intervention trials in developing countries have evaluated the role of zinc supplementation both in prevention and treatment of childhood diseases.

\section{Zinc supplementation in the treatment of acute diarrhea}

Therapeutic usefulness of zinc supplementation in children with acute diarrhea has been summarized recently (see Black \& Sazawal, 2001, this issue). Five controlled clinical trials showed a consistent benefit in reducing the duration and the rate of prolonged diarrhea (i.e. duration $>7$ days). They also reported that a pooled analysis of primary data from four trials showed that there was a modest reduction (by $15 \%$ ) of the probability of diarrhea continuing in the supplemented group. We focus our discussion on two large clinical trials in South Asia (Table 5) one of which was not included in the meta-analysis (see Black \& Sazawal, 2001, this issue). When zinc supplementation is started early (within 3 days of onset) in acute diarrhea a large effect was shown in reducing the rate of prolonged diarrhea episodes (i.e. duration $>7$ days). A study from India (Sazawal et al. $1995)$ in 569 children aged 6-35 months showed a $39 \%$ reduction in the rate of prolonged diarrhea (with $95 \% \mathrm{CI}$ $7 \%, 61 \%$ ). Another study from Bangladesh (Faruque et al. $1998)$ in 681 children aged 6-23 months showed that zinc supplementation was associated with $36 \%$ reduced rate of prolonged diarrhea (95\% CI $4 \%, 57 \%)$. Statistically combining the results (Greenland \& Robins, 1985) of these data (1250 children) from the two studies (Table 5) showed that zinc supplementation could reduce the rate of prolonged diarrhea by $38 \%(95 \%$ CI $16 \%, 54 \%)$. In a controlled trial in 800 children (Bahl et al. personal communication) in India zinc fortified oral rehydration solution was no more efficacious than ordinary oral rehydration solution.

\section{Zinc supplementation in persistent diarrhea}

A remarkable finding of a pooled analysis done by Black \& Sazawal (2001, this issue) was that the rate of treatment failure was markedly reduced; furthermore, deaths were also reduced in the supplemented group. Children with persistent diarrhea would have already been depleted due to loss of zinc in the stool (Castillo-Duran et al. 1988). Zinc supplementation in these children appeared to have an impact on the severity of disease which may have an impact on mortality. The putative mechanisms for the beneficial effect of zinc supplementation in persistent diarrhea have also been reviewed (see Black \& Sazawal, 2001, this issue). As with vitamin A (Table 4), it is worthwhile to investigate whether zinc prevents enteric bacterial translocation and thus, septicemic complications known to be associated with severe malnutrition and persistent diarrhea (Fauveau et al. 1991).

\section{Zinc therapy in the treatment of pneumonia}

Several field intervention trials have shown that zinc supplementation is beneficial in preventing pneumonia in children in developing countries. A pooled analysis (Zinc Investigators Collaborative Group, 1999) has shown that zinc supplemented children had a $41 \%$ reduced rate for pneumonia compared to the controlled group. Given the inconsistency in the definitions used for pneumonia, further studies on this issue are warranted. However, no published study has examined the effect of zinc supplementation on the clinical episode of pneumonia. We could locate two unpublished randomized double blind controlled trials of zinc supplementation therapy of children, one in measles with pneumonia and the other in infants and young children

Table 5. Zinc as adjunct therapy of acute diarrhea on episodes of prolonged diarrhea when administered during illness: two large South Asian studies and results of combined analysis

\begin{tabular}{|c|c|c|c|c|}
\hline & Age & $\begin{array}{c}\text { Rate ratio for } \\
\text { diarrhea }>7 \text { days }\end{array}$ & $95 \% \mathrm{Cl}$ & $P$ value \\
\hline $\begin{array}{l}\text { Sazawal et al. } 1995, \text { India } \\
\text { Zinc }=284, \text { Placebo }=285 \\
6-35 \text { months }\end{array}$ & $6-35 \mathrm{~m}$ & 0.61 & $0.39,0.93$ & 0.02 \\
\hline $\begin{array}{l}\text { Faruque et al. } 1999, \text { Bangladesh } \\
\text { Zinc }=341, \text { Placebo }=340 \\
6-23 \text { months }\end{array}$ & $6-23 \mathrm{~m}$ & 0.64 & $0.43,0.96$ & 0.028 \\
\hline $\begin{array}{l}{ }^{*} \text { Combined results (Mantel-Haenzel, 1959) } \\
\text { Zinc }=625, \text { Placebo }=625\end{array}$ & - & 0.62 & $0.46,0.84$ & 0.002 \\
\hline
\end{tabular}

* Note: These are our analyses of the published data. Sazawal et al. recruited patients at the community clinic level and Faruque et al. 1998 recruited patients in a diarrhea hospital requiring oral rehydration under supervision and followed them in the community. 
with acute lower respiratory infection mostly pneumonia. In one study (Mahalanabis et al. - personal communication), eighty-five hospitalized children with measles and pneumonia were studied (forty-two in zinc and forty-three in placebo groups). The study group received $40 \mathrm{mg}$ of elemental zinc daily for 5 days, forty-three received placebo; there was no difference in the clinical course of illness between the two groups. In this study, $100000 \mathrm{IU}$ of water miscible vitamin A was administered orally on admission to all children which led to a substantial rise in the serum retinol level in either group on day 5 . In the other study, 151 hospitalized children aged 1-24 months with severe acute lower respiratory infection, mostly pneumonia, were randomly assigned to receive either $20 \mathrm{mg}$ zinc daily or a placebo. The supplementation with zinc had no effect on the clinical course of illness compared to the control group. These results are different from what has been obtained with therapeutic trials in acute and persistent diarrhea. However, additional studies with larger sample sizes are required before definite conclusions can be made.

\section{Zinc supplementation in severe protein-energy malnutrition}

Rehabilitation from severe protein-energy malnutrition requires the provision of adequate quantities of macroand micronutrients. Zinc deficiency has been implicated as a limiting factor in recovery (Golden \& Golden, 1981; Hambidge, 1997) and the WHO recommends that all severely malnourished children be treated with zinc along with other micronutrients. A recent randomized double blind trial evaluated varying doses of zinc supplementation on catch-up growth and rehabilitation in 141 children with severe protein-energy malnutrition (Doherty et al. 1998). For ethical reasons a control group with placebo was not used and high-dose zinc supplementation $(6 \mathrm{mg} / \mathrm{kg}$ per day for 15 or 30 days) was compared with low dose supplementation $(1.5 \mathrm{mg} / \mathrm{kg}$ per day). High dose zinc during rehabilitation was not associated with better growth but an unexpected finding was that mortality was more than 6-fold higher among children who received higher zinc doses (rate ratio $=6.3,95 \%$ CI 1.54, 25.84, $P=0.004$; our calculations from the published data). These results indicate that it is important to restrict the dose of zinc to that recommended, i.e. single or double RDA for infants and children with severe protein-energy malnutrition.

\section{Therapeutic use of zinc: policy issues}

Based on the present evidence, the following policy issues on the use of zinc as adjunct therapy for childhood infectious diseases may be considered.

Acute diarrhea. Zinc supplementation renders substantial benefit to all children with acute diarrhea. However, further studies related to effectiveness, cost, operations and safety should be conducted before a more general recommendation for its use is considered. It is important that zinc is not promoted as a 'magic' cure for diarrhea. Efforts should be made to encourage governments to set standards for zinc containing medicinal preparations. A safe and effective dose should be established. For short term therapeutic use a daily dose of $20 \mathrm{mg}$ elemental zinc appears to be safe and adequate.

Persistent diarrhea. Children with persistent diarrhea (i.e. duration $>14$ days) often suffer from varying degrees of protein energy malnutrition. The WHO recommends that all children with persistent diarrhea should receive supplementary multivitamins and minerals at twice the RDA dose of folate, vitamin A, iron, magnesium, copper and zinc. Limited evidence from clinical trials in persistent diarrhea supports the policy of administering zinc along with other micronutrients in persistent diarrhea.

Protein energy malnutrition. The WHO recommends that all severely malnourished children be treated with zinc at twice the RDA dose along with other micronutrients as it is for persistent diarrhea. A recent treatment trial cautions against the use of very large doses of zinc as adjunct therapy for severe protein-energy malnutrition. Furthermore, there is no evidence that two RDA are better than one RDA dose of zinc in severe protein-energy malnutrition.

Malaria. Recently, a population based randomized trial supported by the WHO in West Africa showed that zinc supplementation had no effect on falciparum malaria morbidity. Any policy decision on the therapeutic use of zinc in malaria would need validation by additional controlled clinical trials.

\section{Folic acid in the treatment of acute diarrhea in children}

Folic acid has a key role in DNA synthesis (Weinestein, 1974; Rodriguez, 1978) and assists in the renewal of small bowel mucosal epithelial cells by accelerating the regeneration of damaged cells. Folic acid deficiency, which may lead to an impairment of both cell mediated and humoral immunity, not only caused more severe rotaviral diarrhea in mice but also resulted in reduced weight gain during recovery (Morrey et al. 1984). In adult tropical sprue, folate supplementation leads to clinical improvement (Tomkins, 1979). In a poorly designed study from South Africa, oral folate was shown to shorten diarrhea duration in children (Haffejee, 1988). A recent randomized placebo controlled trial (Ashraf et al. 1998) in 106 children (age 6-23 months) with acute watery diarrhea showed no impact of folate on clinical severity of disease or its duration. An unpublished study (Arora et al. Personal communication) evaluating the role of folate in persistent diarrhea, showed that folate had no beneficial effect on the clinical course of illness. These studies do not preclude the possibility that folate may prevent serious complications of diarrheal illness such as systemic sepsis and have an impact on diarrhea associated mortality. Experimental data (Table 4) support this contention. Controlled intervention trials with folate supplementation to evaluate any mortality impact may be worthwhile. Presently folate is not recommended as an adjunct therapy of illness episodes in children.

\section{References}

Ahmed R, Jones DB \& Jackson AA (1990) The interaction of vitamin A deficiency and rotavirus infection in the mouse. British Journal of Nutrition 63, 363-373.

Ashraf H, Rahman MM, Fuchs GJ \& Mahalanabis D (1998) Folic 
acid in the treatment of acute watery diarrhea in children: a double-blind, randomized, controlled trial. Acta Paediatrica $\mathbf{8 7}$, $1113-1115$.

Baqui AH, De Francisco A, Arifeen SE, Siddique AK \& Sack RB (1995) Bulging fontanelle after supplementation with 25,000 IU of vitamin A in infancy using immunization contacts. Acta Paediatrica 84, 863-866.

Barclay AJG, Foster A \& Sommer A (1987) Vitamin A supplements and mortality related to measles: a randomised clinical trial. British Medical Journal 294, 294-296.

Beaton GH, Martorell R, L'Abbe KA, Edmonston B, McCabe G \& Ross AC (1993) Effectiveness of vitamin A supplementation in the control of young child morbidity and mortality in developing countries. SCN NEWS 9, 17-23.

Bhandari N, Bahl R, Sazawal S \& Bhan MK (1997) Breastfeeding status alters the effect of vitamin A during acute diarrhea in children. Journal of Nutrition 127, 59-63.

Black RE \& Sazawal S (2001) Zinc and childhood infectious disease morbidity and mortality. British Journal of Nutrition $\mathbf{8 5}$, S125-S129.

Castillo-Duran C, Vial P \& Uauy R (1988) Trace mineral balance during acute diarrhea in infants. Journal of Pediatrics 113, $452-457$.

Coutsoudis A, Broughton M \& Coovadia M (1991) Vitamin A supplementation reduces measles morbidity in young African children: a randomised placebo-controlled, double-blind trial. American Journal of Clinical Nutrition 54, 890-895.

de Francisco A, Chakraborty J, Chowdhury HR, Yunus M, Baqui AH, Siddique AK \& Sack RB (1993) Acute toxicity of vitamin A given with vaccines in infancy. Lancet 342, $526-527$.

Dignoss AU \& Podolsky DK (1993) Cytokine modulation of intestinal epithelial restitution: Central role of transforming growth factor. Gastroenterology 105, 1323-1332.

Doherty CP, Sarkar MAK, Shakur MS, Ling SC, Elton RA \& Cutting WA (1998) Zinc and rehabilitation from severe proteinenergy malnutrition: higher-dose regimens are associated with increased mortality. American Journal of Clinical Nutrition $\mathbf{6 8}$ $742-748$.

Ellison JB (1932) Intensive vitamin therapy in measles. British Medical Journal iii, 708-711.

Faruque ASG, Mahalanabis D, Haque SS, Fuchs GJ \& Habte D (1998) Double-blind, randomized, controlled trial of zinc or vitamin A supplementation in young children with acute diarrhea. Acta Padiatrica 87, 1-7.

Fauveau V, Yunus M, Zaman K, Chakraborty J \& Sarder AM (1991) Diarrhea mortality in rural Bangladeshi children. Journal of Tropical Pediatrics 37, 31-36.

Fawzi WW, Moise RL, Fataks M, Herrera MG, Kawau F \& Ndossi G (1996) Effect of vitamin A supplements in reducing seventy of lower respiratory infections among children in Tanzania. Presented to the meeting of the International Vitamin A Consultative Group in Guatemala in March 1996. Guatemala, IVACG (Abstract No. XVII).

Ghishan FK (1984) Transport of electrolytes, water and glucose in zinc deficiency. Journal of Pediatric Gastroenterology and Nutrition 3, 608-612.

Glick AB, McCune BK, Abdulkarem N, Flanders KC, Lumadue JA, Smith JM \& Sporn MB (1991) Complex regulation of TGF (expression by retinoic acid in the vitamin A deficient rat). Development 111, 1083-1086.

Gmoshinaldi IV, Khvylin SI \& Kon VI (1987) Effect of vitamin A deficiency on permeability of the small intestine mucosa for macromolecules in adult rats. Bulletin of Experimental and Biological Medicine 103, 179-182.

Golden MHN \& Golden BE (1981) Effect of zinc supplementation on the dietary intake, rate of weight gain and energy cost of tissue deposition in children recovering from severe malnutrition. American Journal of Clinical Nutrition 34, 900-908.

Greenland S \& Robins JM (1985) Estimation of a common effect parameter from sparse follow-up data. Biometrics 41, 55-68.

Gudas IJ, Sporn MB \& Robert AB (1994) Cellular biology and biochemistry of the retinoids. In The Retinoids: Biology, Chemistry and Medicine, pp. 443-520 [MB Sporn, AB Robert and DS Goodman, editors]. New York: Raven Press.

Haffejee IE (1988) Effect of oral folate on duration of acute infantile diarrhea. Lancet ii, 334-335.

Hambidge KM (1997) Zinc deficiency in young children. American Journal of Clinical Nutrition 65, 160-161.

Henning B, Stewart K, Zaman K, Alam AN, Brown KH \& Black RE (1992) Lack of therapeutic efficacy of vitamin A for non-cholera, watery diarrhea in Bangladeshi children. European Journal of Clinical Nutrition 46, 437-443.

Hossain S, Biswas R, Kabir I, Sarker S, Dibley M, Fuchs G \& Mahalanabis D (1998) Single dose vitamin A treatment in acute shigellosis in Bangladeshi children: randomized double blind controlled trial. British Medical Journal 316, 422-426.

Hussey GD \& Klein M (1990) A randomised, controlled trial of vitamin A in children with severe measles. New England Journal of Medicine 323, 160-164.

Kjolhede CL, Chew FJ, Gadomsks AM \& Marroquin DP (1995) Clinical trial of vitamin A as adjuvant treatment for lower respiratory tract infections. Journal of Pediatrics 126, 807-812.

Mahalanabis D, Rahman MM, Wahed A, Islam MA \& Habte D (1997) Vitamin A megadoses during early infancy on serum retinol concentration and acute side effects and residual effects on 6 month follow-up. Nutrition Research 17, 649-659.

Mantel N \& Haenszel W (1959) Statistical aspects of the analysis of data from retrospective studies of disease. Journal of National Cancer Institute 22, 719-748.

Morrey JD, Sidwell RW, Noble RL, Barnett BB \& Mahoney AW (1984) Effects of folic acid malnutrition on rotaviral infection in mice. Proceedings of Social and Experimental Biology of Medicine 176, 77-83.

Nacul LC, Kirkwood BR, Arthur P, Morris SS, Magalhaes M \& Find MCDS (1997) Randomised, double blind, placebo controlled clinical trial of efficacy of vitamin A treatment in non-measles childhood pneumonia. British Medical Journal 13, $1008-1013$.

Nzegwu HC \& Levin RJ (1992) Vitamin A deficiency and colonic electrogenic absorption and secretion in the rat. Gut 33, 794-800.

Patrick J, Golden BE \& Golden MHN (1978) Effect of zinc on leucocyte sodium transport in vitro. Clinical Science and Molecular Medicine 54, 585-587.

Patrick J, Golden BE \& Golden HN (1980) Leucocyte sodium transport and dietary zinc in protein energy malnutrition. American Journal of Clinical Nutrition 33, 617-620.

Quinlan KP \& Hayani KC (1996) Vitamin A and respiratory syncytial virus infection. Archives Pediatric and Adolescent Medicine 150, 25-30.

Rahman MM, Mahalanabis D, Wahed A, Islam MA \& Habte D (1995) Administration of 25,000 IU vitamin A doses at routine immunization in young infants. European Journal of Clinical Nutrition 49, 439-445.

Rodriguez MS (1978) A conspectus of research on folacin requirements of man. Journal of Nutrition 108, 1983-2075.

Roy SK, Drasar BS \& Tomkins AM (1986) The impact of zinc deficiency on the intestinal response to cholera toxin. Proceedings of Nutritional Society 45, 39A.

Sazawal S, Black RE, Bhan MK, Bhandari N, Sinha A \& Jalla S (1995) Zinc supplementation in young children with acute diarrhea in India. New England Journal of Medicine 333, 839844. 
Shoda R, Mahalanabis D, Islam KN, Wahed MA \& Albert MJ (1996) Effect of vitamin A supplementation on lectin-induced diarrhea and bacterial translocation in rats. Nutrition Research 16, 459-465.

Stabell-Benn C, Bale C, Pedto da Silva A, Oslen J \& Abby P (1995) No evidence of fontanelle-bulging episodes after vitamin A supplementation of 6- and 9-month-old infants in Guinea Bissau. European Journal of Clinical Nutrition 49, 73-74.

Tomkins AM (1979) Folate malnutrition in tropical diarrheas. Transactions of the Royal Society of Tropical Medicine and Hygiene 73, 495-502.

Weinstein WM (1974) Epithelial cell renewal of the small intestinal mucosa. Medical Clinics of North America 58, 1375-1386.
Welsh PKS, Farmery SM, MacLennan K, Sheridan MB, Barclay GR, Guillou PJ \& Reynolds JV (1998) Gut barrier function in malnourished patients. Gut 42, 396-401.

World Health Organization/CHD Immunization-Linked Vitamin A Supplementation Study Group (1998) Randomized trial to assess benefits and safety of vitamin A supplementation linked to immunization in early infancy. Lancet 352, pp. 1257-1261.

Zile M, Bunga C \& Dlues HF (1977) Effect of vitamin A deficiency on intestinal cell proliferation in the rat. Journal of Nutrition 107, 552-560.

Zinc Investigators Collaborative Group (1999) Prevention of diarrhea and pneumonia by zinc supplementation in children in developing countries: pooled analysis of randomized controlled trials. Journal of Pediatrics 135, pp. 689-697. 